\section{Familienunternehmen startet in Kapfenberg neu durch}

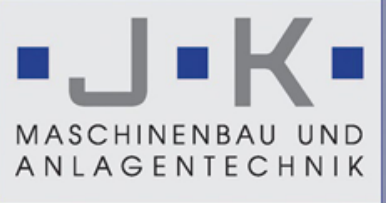

Die Johann Knorr Maschinenbau und Anlagentechnik GmbH wurde an der ehemaligen Adresse der Produktionsstätte der Knorr Technik GmbH neu gegründet

Aufgrund von Umstrukturierungen wurde die Produktionsstätte der Knorr Technik GmbH in Kapfenberg mit Ende September 2015 geschlossen. Mit 01. Oktober 2015 hat die neu gegründete Johann Knorr Maschinenbau und Anlagentechnik $\mathrm{GmbH}$ die Produktion am selben Standort am Burgstallweg 25a für Sondermaschinen und Sonderanlagen für die Stahlindustrie aufgenommen.

Der Betrieb hat mit einem Team des bewährten Stammpersonals gestartet. Der Liefer- und Leistungsumfang wurde anlässlich der Firmenneugründung wesentlich erhöht. Das Leistungsspektrum wird durch die Kooperation mit der ebenfalls in Kapfenberg neu gegründeten International Steel Consulting $\mathrm{GmbH}$,

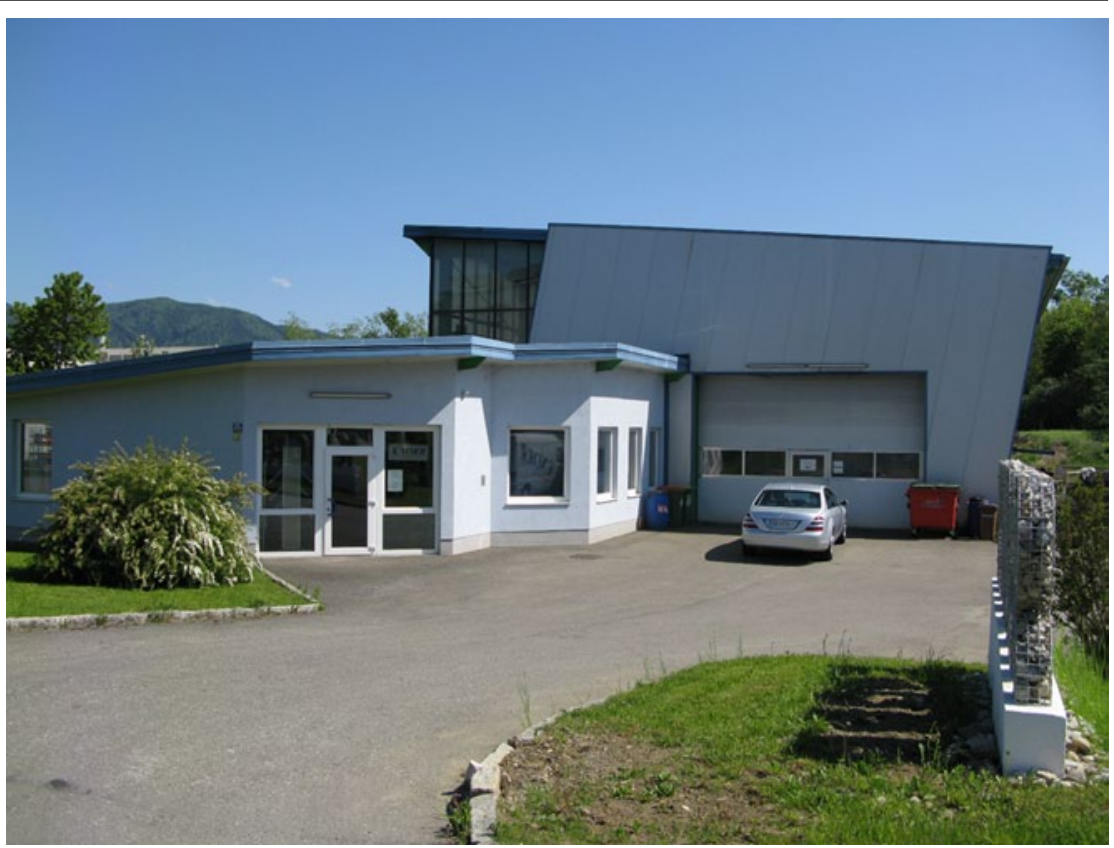

die umfassende Beratungs- und Planungstätigkeiten für die Stahl- und Metallindustrie anbietet, ergänzt. Durch diese enge Zusammenarbeit können Neuplanungen und Modernisierungen ganzer Betriebsstätten einschließlich Projektabwicklung, Kosten- und Terminverfolgung angeboten werden. Das renommierte Familienunternehmen verfügt über mehr als vier Jahrzehnte Erfahrung unter anderem mit Sondermaschinen- und Sonderanlagenbau nicht nur in Österreich, sondern auch weltweit.

Neben Maschinen- und Anlagenbau für Stahl- und Walzwerke umfasst das Angebotsspektrum auch die Ferti- gung von Verschleiß- und Ersatzteilen, die Durchführung von Konstruktionsarbeiten, die Fertigung von Einrichtungen basierend auf kundenseitig beigestellter Zeichnungen und komplett verkettete Anlagen mit Steuerungs- und Regelungstechnik. Darüber hinaus befasst sich das Unternehmen mit mechanischen und elektrischen Überstellungen von Maschinen und Anlagen inklusive Inbetriebnahme sowie Reparatur- und Instandhaltungsarbeiten und stellt auch Leihpersonal zur Verfügung. 